\title{
Initiating Decolonial Praxis: Childhood Studies Curricula in an English University
}

\author{
Dimitrina Kaneva* $^{\text {a* }}$ J. Bishop ${ }^{\mathrm{a}}$ and N.E. Whitelaw ${ }^{\mathrm{a}}$ \\ ${ }^{a}$ School of Education and Professional Development, University of Huddersfield, \\ Huddersfield, UK
}

Dimitrina Kaneva (corresponding author)

University of Huddersfield

School of Education and Professional Development

Queensgate

Huddersfield HD1 3DH

United Kingdom

E: d.kaneva@hud.ac.uk

T: +44 1484478106

ORCiD: 0000-0002-5965-5285

Jo Bishop

University of Huddersfield

School of Education and Professional Development

Queensgate

Huddersfield HD1 3DH

United Kingdom

E: j.bishop@ hud.ac.uk

Nicole E. Whitelaw

University of Huddersfield

School of Education and Professional Development

Queensgate

Huddersfield HD1 3DH

United Kingdom

E: N.E.Whitelaw@hud.ac.uk

This is an Accepted Manuscript of an article published by Taylor \& Francis in Third World Thematics: A TWQ Journal on [date of publication TBC], available online: https://doi.org/10.1080/23802014.2020.1762511 


\title{
Initiating Decolonial Praxis: Childhood Studies Curricula in an English University
}

\author{
English universities aim to attract students from various backgrounds. However, the needs of \\ such cohorts require curricula to be relevant and accessible to an audience that does not \\ necessarily identify as traditionally academic. At disciplinary level there have also been calls \\ for increasing the plurality of knowledge practices and perspectives. Here, we consider our \\ efforts to reflect on and decolonise Childhood Studies curricula through three topics: global \\ childhoods, disabled childhoods, and transgender/gender non-conforming childhoods. These \\ case studies illustrate a decolonial turn in students engaging with differently constructed \\ childhoods through content that challenges their thinking of childhood from a Western \\ heteronormative, non-disabled perspective. We begin to decolonise our curricula through \\ working with children's voices and challenging practices that marginalise children and \\ position their experiences as 'other'.
}

Keywords: Childhood Studies; decolonising curricula; voice; othering

Movements to decolonise the university have caused much controversy while exposing a pressing need to diversify Eurocentric curricula and reading lists (Bhambra et al. 2018). In England, decolonisation considerations are particularly relevant to Post-1992 universities, which contrary to red-brick Russell Group institutions, tend to attract students from backgrounds framed as not traditionally academic, i.e. first-generation university students, working class students, and mature students. Post-1992 universities are specifically focused on widening access and participation to higher education through teaching quality and additional resources that support students to excel in an environment where they may lack the needed social, cultural and economic capital (Pursglove and Simpson 2007). Access to university thus goes beyond physical presence towards developing a sense of belonging and a multitude of perspectives that reflect the student body (Mbembe 2016). Working in a Post1992 university, we see ourselves as agents in the movement to decolonise our course, not only in terms of questioning Eurocentric knowledge dominance (Mignolo 2011), but also in 
instituting forms of teaching and learning that position students' backgrounds and knowledge as a learning resource.

In this paper we discuss our initial attempts to decolonise Childhood Studies (CS) curricula through the introduction of specific sessions to stretch and challenge students' thinking and learning. We consider the framing of global childhoods, disabled childhoods and transgender and gender non-conforming childhoods in our English context with a view of how colonial thought and Eurocentric knowledge practices have influenced much of the teaching and literature around children and their lives. In doing so, we rethink our broad subject area in relation to decolonial movements and disciplinary debates and interrogate our pedagogic practice through examples of challenging students' preconceptions about childhood whilst reflecting on our own positionality.

CS is a highly contested multi-disciplinary field (Punch 2016) where children are conceptualised differently in disciplinary and historical terms. Much of the teaching is informed by the sociology of childhood seeing childhood as socially constructed and children as agents (Hammersley 2017). Yet, this seemingly self-explanatory notion of agency is highly problematic when applied without contextual considerations of its authenticity (James 2007). Situated in what is described a 'multicultural society' (Ashcroft and Bevir 2018), we are expected to reflect this in our practice. However, we are far from arguing that diversity policies and practices facilitate decolonial projects. In reality, focus on multiculturalism and diversity tends to 'other' people (Ahmed 2009) and children from different backgrounds. In the British education sector there is a tendency to make difference, and specifically race, exotic rather than incorporate it in school curricula as a critical angle. The practice of ascribing identities to children based on their family origin is deeply problematic because it encourages Black and Asian children to associate with an origin that is not representative of their experiences of growing up in Britain (Wells 2018). We started decolonising our 
curriculum when it became clear that our students may have had such experiences throughout their compulsory education. They were potentially further excluded from higher education through curricula that did not reflect their backgrounds and childhood experiences. We thus intended for our curricula to challenge thinking and experiences, rather than merely provide a diversity of perspectives.

As lecturers we occupy positions of power in terms of knowledge hierarchies, and in relation to our students and their backgrounds. We see decolonisation as related not only to what is taught (Dennis 2018) but also its communication in the classroom (Bernstein 2000). Otherwise, curricula continue to perpetuate exclusionary ways of thinking in academia. Decolonisation in our context is about making curricula relevant and accessible to the range of students in our cohorts - a large proportion of female students from ethnic minorities, those from more conservative religious backgrounds, students from working class backgrounds, those who are first in their family to study at university, mature students with caring responsibilities, international students and so on. We ought to think critically about how children's lives and experiences are represented in our curricula; not least because some of these experiences resonate with our students' childhoods.

We approach our decolonisation project offering students a multitude of perspectives without attempting to order these. In doing so, we acknowledge our privilege as 'at first glance' white female academics, based in an English institution with resources to challenge and support our students' thinking. We also intend to use this privilege to further develop our curricula as allies to those who have traditionally been marginalised in the academy. However, we are mindful that some of our own non-traditional experiences led us to teaching these topics. 
We believe that in addition to teaching, we should facilitate a space for students to tell their own stories of being positioned as 'other'. This perspective of decolonial practice has not been explored in detail. From this standpoint we see decolonisation as a project that can take place within institutions in the Global North, particularly those claiming to 'widen participation' by encouraging different ethnic and social groups to undertake higher education degres, and not only as emerging from the material conditions of actual experiences of colonisation (Noxolo 2017). In our careers we ended up in academia for broadly similar reasons - dissatisfaction with injustices within the compulsory schooling system at various levels and contexts. We share a desire to foster change for the next generation of practitioners and scholars through exposing the unfairness of social processes that marginalise and silence children framed as 'other' (some of them the very students we teach). We see the project of decolonising the curriculum as a move towards problematising and challenging knowledge discourses that dominate the academy from within while developing critical awareness of the multiplicity of perspectives (Dennis 2018) within CS.

\section{Decolonising Curricula}

The movement to decolonise university curricula questions the epistemology and politics of knowledge maintained in academic contexts, as well as the praxis of disseminating and teaching such knowledge (Icaza and Vazquez 2018). These considerations are entangled with the wider conditions of capitalist modernity and its hidden coloniality (Mignolo 2002). In order to survive financially, universities are hard pressed to recruit and retain students, provide value for money, and satisfy their customers (Mbembe 2016). However, partaking in institutional processes students are subsumed into colonial hierarchies that prioritise Western knowledge and epistemic dependency of the colonised in relation to Western thought (Mignolo 2002). Decolonial practice moves away from universal knowledge and demands rethinking of knowledge practices that are more relevant and responsive to the contexts of 
students. Diversification of content is a necessary prerequisite but falls short of questioning knowledge production practices (Nakata et al. 2012). Yet, we must acknowledge that our starting point was a drive to diversify our curricula before considering the radical transformation involved in decolonisation.

Curriculum relevance concerned us at different levels: the individual student; groups of peoples that tend to be marginalised and/or misrepresented at university and within knowledge hegemonies; and within individual disciplines and disciplinary intersections. In a decolonised university, individuals can relate to what they are taught with knowledge carefully selected and reconstructed to exemplify, question and engage with a multitude of perspectives. Icaza and Vazquez (2018) demonstrate this through the practice of diversity circles and Nakata et al.'s (2012) curriculum development focuses on students as coproducers who engage with questioning their own backgrounds and experiences within the curriculum. A multitude of perspectives should also include those from marginalised and misrepresented groups. This is important in relation to our student body, but also how students are taught about marginalised groups, e.g. ethnic minorities, particularly Black and Asian minorities (in the UK), LGBTQ+, disabled people, women, mature students, and the intersections between these. For example, decolonisation engages with the European origin, race and gender of scholars and the implications for their knowledge production based on power that 'converts differences into values and hierarchies' (Mignolo 2002:71). CS is an interesting area to deconstruct this: while academic literature is largely dominated by male, European scholars, university teaching teams and professionals working with children are disproportionately female (Cheney 2019). Patriarchy maintains colonial power through a guise of expertise and division of labour (Mignolo 2011). Decolonisation thus goes further than destabilising Eurocentric assumptions towards addressing the overreliance on global notions and conceptions and lack of multiple voices in writing about childhood. The 
challenge is who decides what knowledge ought to be included/excluded and whose privilege/marginalisation are reproduced in the process.

Decolonising the curriculum requires questioning knowledge that emerges from Western paradigms. Muller and Young (2019:198) distinguish between 'knowledge of the powerful' and 'powerful knowledge' describing the former as finite, non-transferrable from the power elite, and the latter as a 'non-rivalrous good' which can enhance an education environment and its potential through shared knowledge practices. The perceived objectivity of academic knowledge has allowed university knowledge production to remain largely unchallenged (Icaza and Vazquez 2018) through framing curricula as a socially just mechanism that provides 'access for all' (Rudolph et al. 2018). This is problematic because crudely put, education systems maintain the status quo and the social positions ascribed to particular groups through specialised knowledge (Bernstein 2000) which makes 'access for all' unachievable. In universities, the choice of curriculum content is highly dependent on lecturers who occupy knowledge positions. Rudoph et al. (2018) argue that decolonised 'just' curricula make visible the politics of knowledge production, power relations and positioning that underpin production, rather than arguing the objective nature of such work.

Decolonisation engages with highlighting and reconstructing unequal power dynamics in the production and dissemination of knowledge. Such approaches seek to embed in curricula other types of knowledge produced by marginalised groups to emerge as equally important - e.g. women, working classes, ethnic minorities, LGBTQ+ (Begum and Saini 2019). Within the context of diversifying our curriculum, we approach decolonisation as a project of working with knowledge that is critical for understanding other worldviews in relation to Western knowledge (Nakata et al. 2012). The aim is thus to construct knowledge informed by the perspectives of those who are underrepresented in university curricula, but also to engage students with the complexity of local and global processes from multiple 
points of view without feeling overwhelmed. Learning to feel comfortable with discomfort and uncertainty, and to establish ethical relationships and negotiate principles and values 'in context' are important skills for students (Sathorar and Geduld 2018).

\section{Decolonising Childhood Studies}

CS, as the study of children and childhoods, spans across the social sciences, natural sciences and humanities. However, integrating these disciplines has not been straightforward. CS is currently at crossroads seeking to clarify its focus on the child (Hammersley 2017; Prout 2019; Spyrou 2019). A difficulty with centring the child is a lack of coordination between disciplines where academics, practitioners and policy makers hold different views (Punch 2016). For instance, Wall (2019:8) differentiates between neoliberal perspectives that focus on the agentic individual child governed by international policies; cosmopolitan perspectives of 'equal and universal human rights' centred on an individual; and postcolonial theorisations around difference and empowerment through grassroots. Much of the contemporary study of childhood is reliant on universal concepts and categories permeated by ideas of innocence, social dependency and rights to protection and training that position children as transitional becomings without social or personal autonomy (Wyness 2018). Child development is one example where developmental norms have become a global standard, whilst being benchmarked against what are essentially Western conceptualisations (Burman 2019). There is a further need to steer away from modernist theoretical perspectives that thrive on mutually exclusive dichotomies around geo-political location, gender, dis/ability, development (Prout 2019). Such polarised notions of childhood somewhat simplify the complexity of children and their relational personhood.

Similar is the case of voice, rights, agency - underlying concepts in the United Nations Convention on the Rights of the Child (UNCRC) (UN 1989). While the notion of 
voice is paramount in understanding the experiences of children, and in terms of decolonising the curriculum, there is a pitfall with the Western ideological centredness of the UNCRC that is applied globally (Cheney 2019; Wall 2019; Wells 2015). We do not imply that universal children's rights are a mere generalisation or an act of colonisation; rather we question the idea that such rights are universally applicable. For example, Article 12 (right to voice and participation) has a caveat that children can express their opinions, but such capacity is judged by adults, bringing into question who is deemed capable enough to be heard. Examples of voices that have not merited a place in CS alongside the 'normal' child include: the problem child (Knight 2019); the DisHuman child (Goodley et al. 2016); the Black/Asian child (Graham 2006). The omission of Black and Asian children is not accidental, rather a reflection of the impact of the colonial world and structural racism in social settings (Wells 2018). This has implications for how children are socialised and inducted into social order and how they learn to see themselves. Such theorisation begins to question the notion of children's agency as bearers of universal rights. Cheney (2019) illustrates this point in relation to the blanket minimum age for work issued by the International Labour Organisation (Convention No. 138) arguing that children should have been consulted about the impact of work on their livelihoods rather than assuming universal standards related to age and informed by Western views of childhood.

Established as a discipline in Northern Europe, CS and its decolonisation require engagement with paradoxes around universalism that emerge in practice and a shift away from the child as the centre of study towards focusing on difference and the politics of knowledge across its original context. Wyness (2018) posits that regional conceptions should not be set against global standards of childhood as a 'gold'standard. University curricula tend to focus primarily on global standards dictated by the universal rights paradigm and economic value of children. The idea of children's innocence, dependence and the 
safeguarding of their needs in the light of developmental psychology and the role of mass schooling in preparation for adulthood reinforces modern binaries between child and adult illustrating the impact of colonialism on the governance of children's lives. Yet, Wells (2018) argues that childhood is unequally structured as gendered and racialised which means that in reality, children's rights discourses and global focus on 'child-saving' (p. 155) lead to the exclusions of children who do not fit the 'boy, white, straight, middle class, able and citizen' narrative. We have a responsibility to question how we restructure disciplinary knowledge to reflect wider contexts beyond the initial focus of CS and amplify the voices of children who have been silenced and stigmatised along the lines of race, gender, disability (Wells 2018).

Including challenging issues in our curricula is needed to develop critical thinking in our students and to advance the field of CS while contesting established knowledge production monopolies. To decolonise CS would mean to explore the gap between universal ideas of what childhood is as per the UNCRC and the experiences of marginalised children and their families in different contexts (Cheney 2019). Such analysis involves shifting the focus away from traditional sources of knowledge in the Global North towards local and regional perspectives in context (Burman 2019). Mahabeer (2018) points out difficulties with representing local voices theoretically and calls for understanding the lived realities of children instead, which includes an appreciation that such realities in the Global South are not inevitably linked to poverty, disease or deficiencies (Twum-Danso Imoh 2016). This requires seeing the human child and challenging models of childhood that favour discourses of normalisation (Burman 2019) and universalism. Equally, in the Global North there is a need to move away from pathologising children who appear different (Graham 2006) and positioning groups of children as a problem (Knight 2019). Thus, decolonising CS becomes a process of amplifying both differences and commonalities across contexts through local practices and voice. 
As a team we are at the early stages of decolonisation and over the last year have pondered on the plurality of our curriculum, its representation of childhood, and relevance to our students. Within our practice we have each worked with children and young people narrated as different. We initially aimed to diversify our curriculum to include voices that more accurately and intimately represent children's experiences of difference, however over time we began to recognise elements of decolonial praxis.

\section{Curricula and teaching practice}

Contemporary Childhood Studies (CCS) is a first-year core module running for 24 weeks as a lecture followed by seminars. CCS explores topics that reflect different aspects of childhood. The module utilises the multi-disciplinary nature of CS and invites students to reflect on multiple theoretical perspectives. The sessions are organised thematically and delivered by lecturers who have first-hand personal or professional (or both) engagement with the topic. CCS creates what Dennis (2019) terms a 'cacophony of voices' as a way to begin to uproot students' perceptions from their particular standpoints and experiences of growing up in a Western context. We bring key issues to life through debate and discussion and facilitate the voices of children and young people to allow spaces for students to make sense of these. The emphasis on listening to children's authentic voices carries on throughout the three-year course. As the module is taught in the first year, the concepts are simplified to lay the foundations for students' critical study that follows (Nakata et al. 2012). In relation to each topic, we begin to explore and question students' assumptions about childhood and to develop skills and analytical tools to make explicit children's experiences and lives within specific contexts.

Here we consider three topics that illustrate how our teaching begins to resemble decolonial practice: global childhoods, disabled childhoods, and transgender and gender non- 
conforming childhoods. Delivered by different lecturers, they all share the intention to challenge students' perceptions. The sessions were designed to directly engage students in thinking activities that stretch their understanding with lecturers as facilitators.

\section{Global childhoods}

This session aimed to question the notion of a global childhood in response to efforts to govern children and childhood internationally (Wells 2015), particularly in relation to formal education. We problematised Western notions of childhood through considering children's stories from the Global South in a deliberately simplified manner of contrasting the living and material conditions of children in a familiar and unfamiliar context to reflect students' level of study. We considered the political, economic and socio-cultural dimensions of globalisation leading to uncomfortable assertions about the persistence of inequalities in wealth distribution, the challenges with addressing childhood poverty on a global scale, the idea of children's rights, and the differences between global and local conceptions of childhood (Wyness 2018). We engaged with key documents referring to a global standard of childhood - the UNCRC (UN 1989), the Millennium and Sustainable Development Goals as a strategy to 'fix' childhood experiences through formal education (Wells 2015). As introduction to the Global South, we watched a UK Aid advert (DFID 2018a) inviting students to think whether such material promote a Western bias through narratives about the white saviour and their monetary contribution. At this point students were asked to think about their initial reaction to the video intended as a reflective activity that would contribute to shifting perceptions about the Global South following further investigation of children's lived experiences.

Next, we looked at street-connected children's experiences published in Child Explorer (2014) and the 2017 special issue on street-connected young people of Enabling 
Education Review. These first-hand accounts aimed to challenge students' preconceptions about street-connected children being impoverished, unhappy and disconcerted with their situation: "They use the term "hustler" to communicate their aim of working for their money and developing informal networks with adults engaged in similar work who act as peers or possible employers in the loosest sense' (Corcoran 2014). It was evident that moving on the street was oftentimes a choice of the children themselves, because of the difficulties experienced at home or additional responsibilities they had. Each story revealed difficulties alongside advantages of living on the street, moving away from the idea that formal education is the only option for children. As an alternative, we explored grassroots support with literacy and numeracy skills as means to develop self-sufficiency for children wanting to live independently on the street (Ferguson 2017). Two questions were asked: What did you learn about street-connected childhoods? and Who has a role in shaping these children's lives?

In follow-up discussions, several students were surprised at the positive outcome of the stories, including financial gains, peer networks, informal education opportunities through grassroots organisations, leading to epistemic disobedience (Mignolo 2011) with regards to perceptions of childhood. One student commented that children's agency was revealed through the stories and admitted that she did not expect this to be the case, but now realised that she needed to be mindful about assumptions made based on contextual differences and the multiple ways of being in childhood. It is worth noting that the work we have carried out to exemplify multiple perspectives of childhood was intended to decentre our students' views of childhood which are informed by their Western upbringing and engagement with those from similar backgrounds. Although our cohort represents several ethnicities, these were not representative of different childhood experiences. We identified how our Western ways of thinking can be highly problematic if applied in a different context. Some students expressed 
sadness about children's choice to live on the street, others found it difficult to shake off their preconceptions about what is an 'acceptable' childhood indicating the further work we need to engage in to decolonise our students' thinking and challenge notions of 'acceptable' childhood. To conclude, we suggested that 'normative' and 'global' conceptions of childhood maintain colonial power over other contexts and cause further problems such as strategies that are not fit for purpose, including the removal of children from the street, or focus on formal academic education as the gold-standard solution to poverty.

I (DK) planned this session to illustrate the unquestioned dominance of Western knowledge and practice, which also influence my own positioning. My Eastern European background means I grew up in a post-communist state with restrictions unseen by peers in the West, yet my experiences and expertise are subsumed as Western because of my workplace. Considering the impact of 'global' and thus universal ways of thinking in the context of our students' future practice is important due to increased migration and the relational nature of children and young people's livelihoods and experiences. Sensitivity, awareness and respect for the situations of children across contexts are a prerequisite for any student wishing to work with children.

\section{Barriers to Being: Exploring Narratives of Disability}

In this session I (NW) wanted to prompt students to question their ways of thinking about disability and disabled childhoods, and to 'understand the conceptual limits of their own thinking' (Nakata et al. 2012:121). This involved analysis of the narratives and theories that may have led to ableist perspectives, provoking students to question and challenge ideas about a 'normal' childhood. We started by looking at how psychological approaches of quantifying child development have led to the 'normal child' myth. Considering the implications for children who do not follow 'normal' development patterns, we explored the portrayal of disability in English media: scroungers, baddies or super-humans. We used 
Thomas' (2007) social-relational model of disability to illustrate that the idea of the 'normal child' and media narratives can be seen as 'barriers to being' for disabled children. Our discussion echoed questions asked by Mignolo (2011) about who constructs knowledge and why.

Due to my background as a teacher of teenagers with profound learning difficulties, I wanted to focus our discussions on young people with learning disabilities and explore marginalisation in all aspects of life through the voices of those who remain overlooked and silenced. We started by viewing the video 'In My Language' (Baggs 2007). At first, Baggs (an autistic adult) is seen interacting with her environment, for example running her fingers through water. She can be heard singing and making vocal noises, but not using words. Later, Baggs posits a provocation though the use of a Voice Output Communication Aid: people define personhood through their limited definition of thought and communication. Baggs states 'The way I naturally think and respond to things looks and feels so different from standard concepts ... that some people do not consider it thought at all'. This prompted a discussion of our expectations of people with learning or communication difficulties, and how expectations create barriers to being by othering as a result of normative views of development and language. This felt like a powerful and provocative moment for many students, some of whom questioned their own assumptions about young people they had previously supported. I was also able to examine and question my role in othering disabled pupils as a teacher in the past, albeit with what I considered to be altruistic intentions, as evidence for challenging my own colonial thought bias. The discomfort in discussing my limiting expectations and the results of these demonstrated that we are all responsible to reflect on whether our responses are based on the 'standard concepts' discussed by Baggs, and how we can address these. In order to challenge traditional hierarchies of knowledge, we 
need to focus on the knower rather than the known (Mignolo 2011), and this session allowed some space for reflection on what we know and how we know it.

Students then viewed the online exhibition Rightful Lives (Neary et al. 2018), where people with learning disabilities and/or autism have posted artwork, photographs, videos and writing reflecting on the ways in which their human rights are denied. Students were asked to explore the exhibition and consider what barriers to being (Thomas 2007) they could identify. This activity seemed difficult and unsettling. One group questioned whether being denied the opportunity to line things up and categorise them in an assessment and treatment unit (as seen in the piece 'Orderly Lives') could really be a barrier to being. Another group questioned whether young people with learning difficulties should be allowed to express their sexual identity (as seen in the piece 'Wild Rainbows'). Others felt more comfortable with these aspects of the exhibition, but did not want to see the photographs of the end result of othering shown in the piece 'Reasonable Force'. It was clear that this exhibition challenged and confronted students, and in hindsight we needed more time to follow up on connections between the use of normative approaches to assign worth and value to the lives of others and the pieces in the exhibition.

The session concluded with a hopeful note, looking at What We Love Most About Life (Bonnello 2016), in which autistic children and young people share their joys, interests and things that make them happy. The emphasis here was on the role of schools, services and wider society in learning to see the person rather than the label, allowing students to consider whether this would lead to equity and the upholding of rights.

\section{Transgender and Gender Non-conforming Childhoods}

I (JB) felt it was important that a curriculum setting out to examine contemporary issues in childhood made space for a particularly complex and multifaceted issue which is starting to 
make its presence felt- not least through media coverage which report the lives of transgender (TG) and gender non-conforming (GNC) children sometimes accurately and sympathetically, but more often sensationally and insensitively. The emergence of Trans* as both a culturally recognised issue, and lived reality (albeit covertly by many) is being increasingly recognised (Hines et al. 2018a; Monro 2019). Trans* is an umbrella term originating from transgender communities and activist movements, and encompasses a range of gender identities that fall 'across, between or beyond the categories of male and female as defined at birth', with the asterisk emphasising the inclusion of non-binary, and 'other non-normative gender identities and practices' (Hines et al. 2018b:6). These growing numbers of children and young people present an opportunity to rethink our assumptions and theories about, and practices with children who 'challenge the normative gender grain' of the culture where they have been brought up (Ehrensaft 2014:33). As a white British woman schooled in the notion of gender as a social construct, albeit one which has very real material consequences, and seeing myself as a socialist feminist, I have been surprised with my own struggle to move away from thinking about gender in binary terms. Reading enabled me to build cognitive structures to do so (Monro 2019) but I have also been challenged to reflect upon the current epistemological and political tensions between feminism and Trans* (Hines 2017). Then something significant happened: a transgender child 'showed up' (Ehrensaft 2011) in my family and my desire to decolonise my own thinking about gender became ever more urgent as I had to process the reasons why I struggled to see this person as a self-declared 'he' rather than a 'she'.

This session was a new addition to the curriculum that could be seen as a clumsy attempt to 'bolt-on' the issue to make our curriculum more inclusive, or alternatively diversify content in a tokenistic fashion (Begum and Saini 2018). However, the intention was to explore the binary nature of gender that has led to resistance in understanding TG/GNC 
childhoods. It was important to start by evidencing the impact of the binary concept of gender on the lives of children and young people by using images and ideas with cultural leverage and familiarity to the students. For example, exploring gender expectations before children are born, through examining how the décor of bedrooms differs when being marketed at prospective parents and comparing the aisles in toy shops, noting contrasts in colour, wording and size for toys aimed at girls or boys. We also examined how the introduction of a gender binary is reinforced through the increasing popularity of 'gender reveal' parties in Western countries where guests are invited to witness the announcement of whether the unborn baby will be 'he' or 'she' through association with particular colours or activities.

A series of reflective questions were posed as juxtaposition to the images: (But) what happens if a child sometimes feels like one gender, and at other times another gender? What happens if a child feels they do not have a gender identity? What happens if the gender a child feels or knows that they are, is in direct conflict with the body they have? This exercise required students to imagine how it would feel to be at odds with the gendered world, highlighting that TG/GNC children are potentially 'othered' because they do not fit into binary gender categories. To initiate discussions, we watched videos created by transgender children (ABC News 2013; Buzzfeed 2016) and the award-winning children's documentary I am Leo (CBBC 2014) which was discussed in more depth during the seminar. With the intention of developing a sensitive professional language, a glossary of Trans* gender-related terms was handed out for discussion. Here we started with 'sex', 'gender' and 'cis-gender' so that ideas and beliefs connected with these terms were first understood and only then considered critically. Most students were not familiar with the latter term, demonstrating our taken-for-granted affirmed-at-birth gender. Finally, we looked at how mainstream news media have responded to transgenderism. Headlines asking 'Why are we letting the trans lobby hijack childhood?' further imploring 'Where have all the grown-ups gone?' were 
discussed as examples of how childhood is viewed within the dominant discourse, highlighting disciplinary tensions around seeing children as competent agents or as vulnerable minors in need of adult protection. In planning future sessions, I intend drawing on the writings of practitioners who, in working with a range of children and young people exploring their gender, offer schematic subcategories of gender-non-conforming children which expand the umbrella terms of TG/GNC (Ehrensaft 2011). I would also seek to include academic accounts which document Trans* experiences in the Global South (Vilane 2018) to challenge views that Trans* is a Western phenomenon.

\section{Discussion: Decolonising Curricula through Voice}

In our teaching examples we illustrated initial efforts to decolonise our curriculum by considering global and geographical distinctions, dis/ability and gender. This was a sustained effort to challenge dominant theoretical constructions framed by Western values and knowledge though topics that represent childhoods shaped by colonial thinking in terms of children's positioning in society in relation to adults, the idea of the able body as a 'norm' and gender as a binary (Mignolo 2011). We did not adopt theories originating in the Global South, rather we intended to disrupt students' deeply rooted and oftentimes unchallenged ideas about children and their childhoods. From a Global North perspective, one that is familiar to our students, we began to scaffold understanding of differences and commonalities across childhood experiences in various contexts. We used images, videos and text that build on children and young people's voices describing their specific contexts and experiences as an attempt to explore the knowledge within these voices. We outlined the content arguing that the sessions enabled us to begin decolonisation. Children and childhoods may not be directly comparable across contexts, but they share similarities which allow us to draw parallels based on the experiences of certain groups of children being marginalised (Punch 2016). Such topics are timely in exploring colonial influences in our own context and 
the experiences of groups that are being excluded in order to maintain the local relevance of teaching (Mampane et al. 2018). However, we acknowledge that building understanding is ongoing work with the aim to expand the range of theories that students explore (Nakata et al. 2012).

We reflect on the place and importance of voice to decolonise our curriculum as a project that requires engagement with understanding the perspectives of marginalised and 'othered' children, and equally their humanness (Desai and Sanya 2016). We are also mindful of the paradox in empowering children to speak for themselves as the role of adults in protecting and making decisions about children requires filtering of the questions that are being asked and choosing who speaks to answer them (Wall 2019). This makes the notion of children's voice somewhat problematic and requires us, as lecturers in positions of power/privilege, to continuously reflect on our selection of content and interpretations of voices. As discussed in the case studies, we deliberately did not offer solutions or interpretations, rather let voices speak for themselves and trouble our students, leading to more questions. Thus, Muller and Young's 'powerful knowledge' (2018) serves well to describe what we set out to do in delivering this module: develop potential for transferability of knowledge and experiences through marginalised voices from tutor to student, student to student and back again as a conceptual link to decolonising the curriculum.

Much of our students' understanding of child development stems from a normative model that starts from birth, with growth and development tracked against a 'typical' trajectory which is at odds with the notion of voice. Extended childhood through adolescence is certainly not a global norm but has gradually been disseminated through the rest of the world (Wells 2018). This builds on ideas of childhood that are not representative of the contexts they are imposed on, a characteristic of colonial power and its entanglement with the Global South (Mignolo 2002); for example, the role of formal education as means to 
developing economically capable citizens. Exploring global childhoods, we focused on international development initiatives that promote education as the solution to poverty. Formal academic education is a Western construct, so considering street-connectedness and informal education initiatives as an alternative was an attempt to decolonise understandings of children's occupations that are of value. We deliberately contrasted Western childhoods with the stories of street-connected children to foster questions about voice and representation. It emerged that our students had no first-hand experience with the Global South yet had formed ideas through the mass media of how children live and their limited access to resources. The focus on children's stories created space to explore the context of the street and how it could empower children - a finding that was particularly useful in reclaiming street-connected children's humanity. This destabilised the aid and saviour narrative often seen in the UK (see DFID 2018b) aiming to fix children's lives and offered a pedagogy of solidarity (Desai and Sanya 2016) to exemplify the voice and value of the human child.

Focusing on disability allowed us to further trouble normative developmental trajectories (Goodley et al. 2016). Garland-Thomson (2014) describes disability as 'interruption to the continuity of sameness', which encouraged our students to consider the world from different standpoints. The authentic voice of disabled youth demonstrated the value of different ways of thinking, in a world where the ways people think, communicate and interact 'determine whether you are seen as a real person at all' (Baggs 2007). This echoes Goodley et al.'s (2016) notion of the DisHuman child who simultaneously troubles and reshapes notions of 'normality' and asserts disabled children's humanity. A DisHuman position, or a consideration of what it means to be human, and a child specifically, allows us to reject the notion that there is a 'typical' developmental trajectory and instead focus on the multitude of trajectories of children as humans. The focus on the child and their humanity in 
each of the contexts we discuss is paramount in decolonising our curriculum. To an extent we reclaim humanity and question typical conceptions of it through the voices of children and young people. The idea of the DisHuman thus helps us to reflect on the 'posthuman condition' (Braidotti 2013:13) and to 'move to a time when thinking about the human will always involve thinking about disability' (Goodley and Runswick-Cole 2016:13), asserting the importance of exploring children's humanness and their experiences while fostering a deeper understanding of difference.

Normative trajectories and biological determinism equally fail in relation to TG/GNC childhood experiences. The de-coupling and conceptual interrogation of sex and gender forms a traditional diet of sociological teaching that gendered behaviour results from social constructivism rather than biology. Although social constructivism originates from the struggles of feminists in their bid to decolonise gender from essentialism, gender remains a predominantly binary and immutable concept (Cook-Daniels 2013). Other disciplines reject this either/or positioning, in exploring more dialectical understandings of gender as being both born and made, that is, as a tension between body and psyche, body and culture and psyche and culture (Ehrensaft 2014), and thus asserting the human nature of TG/GNC children. In teaching about TG/GNC childhoods from the perspective of how cultural norms and social expectations are transgressed by combining gender, we troubled students' preconceptions through destabilising binary thinking and considering different accounts of the world (Sathorar and Geduld 2018). Not making assumptions about students' prior experiences or knowledge of TG/GNC issues was important to let the voices of children speak for themselves. As a result, responses to the content varied from a relatively small number of students who did not understand what they had watched, asking their peers 'What just happened? Was that a girl or a boy?' through to others appearing comfortable and familiar with the content recommending the voices of other Trans* activists and allies to be 
explored. The starting points within the cohort were highly differentiated and these positions needed sensitive and thoughtful consideration. Overall, small-group discussions came across as guarded and tentative. It was possible however, to observe genuine attempts to overcome the cognitive dissonance that was being felt and voiced in order to question and shift from viewing gender as a binary concept. Cook-Daniels (2013:2) notes this process can be both uncomfortable and alarming due to the limited cognitive scaffolding that we possess to 'unthink' gender, arguing '... it doesn't usually occur to us that our gender is a label; it's what we are - inherently and essentially'. Questioning taken-for-granted knowledge and concepts is a first step towards decolonising curriculum content and our own thinking (Nakata et al. 2012).

Focusing on children's voice and its authenticity in the texts, photos and videos provided for students as as a way of deciphering children's experiences (James 2007), we consider the trajectories of our students as future professionals working with children. Decolonisation attempts should engage with multiple perspectives, but they must go beyond to enable students to become allies in their careers. This is particularly relevant because of adults' roles in children's lives. For example, disabled children are 'othered' and dehumanised through being subject to the professional 'gaze' (Tisdall 2012), similarly those from particular ethnic backgrounds are ‘narrated into being problem children’ (Knight 2019). Framing children with regards to their deficiencies pathologises and medicalises them, threatening to remove humanness from those being gazed upon. This includes silencing, with adults in privileged, professional positions (including academics) determining what counts as voice, interpreting what children might be saying and representing this by translating it into more 'official' forms (Graham 2006; Tisdall 2012). The Rightful Lives exhibition by a range of disabled people (including children) about ways in which their rights have been infringed (Neary et al. 2018), counteracts silencing by giving disabled people a space to have their 
voices heard. Whilst the exhibition is curated with artworks categorised according to specific articles from the Human Rights Act, there is no attempt to explain any piece. It equally provided a much-needed space for our students to explore differently constructed knowledge and the 'other' in their uniqueness (Mignolo 2011). Decolonial practice requires recognising and reflecting on our own positions that may expose and challenge power imbalances (Begum and Saini 2018). As a team of white, female, non-disabled lecturers our role was to step away from our privileged knowledge positions and allow other voices to speak and be heard. The voice of the disabled child thus spoke through the exhibition, without a more capable or knowledgeable other providing interpretations.

The notion of voice was important in relation to our students. We needed to provide language, terminology and theoretical lens that enable students to think about the subject critically (Nakata et al. 2012) and begin to voice their learning without falling into the professional gaze trap (Tisdall 2012). Desai and Sanya (2016) argue that curricula work as a mechanism for social regulation and thus decolonising it means to move away from language that marginalises and 'others'. For example, the discourse around 'developed and developing countries' in relation to the Global North and South is common in students' vocabulary so the global childhoods session included reference to appropriate language and a critique of colonialism that focuses on a continuum of development (Punch 2016). In relation to disability, Thomas' (2007) social-relational model emphasised 'barriers to being' as a key aspect of the external disablement of people through structural, systemic and/or individual attitudes, words or actions that have a negative impact on a person's sense of self. A focus on these barriers allowed students to begin the process of 'theoretical and practical reconsiderations of normality' (Tisdall 2012:183). Lastly, TG/GNC terminology is fast-paced and still evolving necessitating a 'glossary' in the session. Moving forward, it is important to explore and think more critically about language and terminology beyond using one 'off-the- 
shelf' glossary, but a variety of sources, each offering its own specialism through the authentic voices within child and young person-led social media platforms, for example.

In its nature, a decolonised education is activist and makes use of the language, space and authorial voice that we have as lecturers. Decolonisation is a process of highlighting the local versions of realities and developing knowledge that is relevant to students within their specific socio-cultural contexts whilst in line with globalisation processes (Mampane et al. 2018). We have begun to illustrate this in our practice by providing 'bodies of knowledge which equip students to participate culturally in particular spaces, providing them with a 'feel for the game' (Dennis 2018:197). While decolonisation has no prescribed roadmap (Sathorar and Geduld 2018), a key purpose is to bring about social change through education. It is hoped that students completed the module with the confidence to recognise and call out practices, beliefs and language that render marginalised children less than fully human.

\section{Conclusion}

Our decolonisation efforts are only the beginning of a long and complex process of challenging students' perspectives, our own views and socialisation into academia. Decolonial praxis goes further than merely introducing new or marginalised voices, it is a reflexive and epistemologically complex task. In the process of writing this article, we have had discussions to pin down terminology, notions and assumptions and this made us question our practice and beliefs on several occasions. Through our responsibility to decolonise our curriculum for the sake of our students, it has become clear that we must abstain from making assumptions about these same students based on their backgrounds. Instead, as a team, we need to further explore ways in which knowledge can be co-produced with students and groups of children that more accurately reflect the multiplicity and relational nature of experiences. The authentic perspectives of marginalised groups tend to provide a more 
genuine insight into reality than the dominant knowledge of the powerful. In this light, we continue our project to curate a dissonance through children's experiences and challenge ourselves further through learning about other ways of being.

\section{References}

ABC News. 2013. "Transgender at 11: Listening to Jazz Jennings.” Accessed September 30 2019. https://www.youtube.com/watch?v=bJw3s85EcxM\&feature=youtu.be

Ahmed, S. 2009. "Embodying diversity: problems and paradoxes for Black Feminists." Race Ethnicity and Education, 12(1):41-52, DOI: 10.1080/13613320802650931

Ashcroft, R.T., and Bevir, M. 2018. "Multiculturalism in Contemporary Britain: Policy, Law and Theory." Critical Review of International Social and Political Philosophy 21(1):1-21.

Baggs, A. [silentmiaow]. 2007 “In My Language.” Accessed September 302019. https://www.youtube.com/watch?v=JnylM1hI2jc\&t=12s

Bhambra, G.K., Gebrial, D., Nişancıoğlu, K. 2018. Decolonising the University. London: Pluto Press.

Begum, N., and Saini, R. 2019. "Decolonising the Curriculum." Political Studies Review 17(2):196-201

Bernstein, B. 2000. Pedagogy, Symbolic Control and Identity. Theory, Research Critique. Oxford: Rowman \& Littlefield.

Bonnello, C. 2016. What We Love Most About Life: Answers from 150 Children across the Autism Spectrum. London: UK Book Publishing.

Braidotti, R. 2013. The Posthuman. Cambridge: Polity Press. 
Burman, E. 2019. "Child as Method: Implications for Decolonising Educational Research." International Studies in Sociology of Education 28(1):4-26.

Buzzfeed News. 2016. "My Gender Transition from Female to Male.” Accessed March 27 2019. https://www.youtube.com/watch?v=RYuipbRGu5s\&feature=youtu.be

CBBC. 2014. “I am Leo.” My Life Series 6, Episode 1. Accessed June 182019. https://www.youtube.com/watch?v=0x_u2cs8DpI

Cheney, K. 2019. "Decolonizing Childhood Studies: Overcoming Patriarchy and Prejudice in Child-related Research and Practice.” In Reimagining Childhood Studies, edited by S. Spyrou, R. Rosen, D.T. Cook, 91-104. London: Bloomsbury.

Cook-Daniels, L. 2013. “Thinking about the Unthinkable: Transgender in an Immutable Binary World.” New Horizons in Adult Education and Human Resource Development 24(1):63-70.

Corcoran, S.L. 2014 “A Day in the Life of a Child: The Opportunities and Dangers of Being Street-Connected in Kenya." Child Explorer 1(3):6-8.

Dennis, C.A. 2018. “Decolonising Education: A Pedagogic Intervention.” In Decolonising the University, edited by G.K. Bhambra, D. Gebrial, K. Nişancığlu, 190-207. London: Pluto Press.

DFID. 2018a. Connecting Classrooms: Ending Poverty by Educating Children Throughout the World. Accessed June 232019.

https://www.youtube.com/watch?v=BJciqbp9KgU\&feature=youtu.be

DFID. 2018b. DFID Education Policy. Get Children Learning. London: DFID.

Desai, K., and Sanya, B.N. 2016. "Towards Decolonial Praxis: Reconfiguring the Human and the Curriculum." Gender and Education 28(6):710-724. 
Ehrensaft, D. 2011. "Boys Will Be Girls, Girls Will Be Boys.” Psychoanalytic Psychology 28(4): 528-548.

Ehrensaft, D. 2014. "Listening and Learning from Gender Nonconforming Children." The Psychoanalytic Study of the Child 68(1):28-56.

Ferguson, V. 2017. "Enabling Education for Long-term Street-connected Young People in Kenya." Enabling Education Review 6:45-47.

https://www.eenet.org.uk/resources/docs/EER6_SCC_final.pdf

Garland-Thomson, R. 2014. “The Story of My Work: How I Became Disabled.” Disability Studies Quarterly 34(2). doi: 10.18061/dsq.v34i2

Goodley, D., and Runswick-Cole, K. 2016. "Becoming Dishuman: Thinking about the Human through Dis/ability." Discourse: Studies in the Cultural Politics of Education 37(1):115.

Goodley, D., Runswick-Cole, K., Liddiard, K. 2016. “The DisHuman Child.” Discourse: Studies in the Cultural Politics of Education 37(5):770-784.

Graham, M. 2006. "Giving Voice to Black Children: An Analysis of Social Agency.” The British Journal of Social Work 37(8):1305-1317.

Hammersley, M. 2017. “Childhood Studies: A sustainable Paradigm?” Childhood 24(1):113127.

Hines, S.2017. "The Feminist Frontier: On Trans and Feminism.” Journal of Gender Studies 28(2):145-157.

Hines, S., Baynham, M.J., Allen, K., Elley, S.T. 2018a. Living Gender in Diverse Times. University of Leeds. https://living-gender.leeds.ac.uk/about/ 
Hines, S., Davy, Z., Monro, S., Motmans, J., Santos., Van Der Ros. 2018b. “Trans* Policy, Practice and Lived Experience within a European Context." Critical Social Policy 38(1):512.

Icaza, R., and Vazquez, R. 2018. "Diversity or Decolonisation? Researching Diversity at the University of Amsterdam.” In Decolonising the University, edited by G.K.Bhambra, D.Gebrial, K.Nişancığlu, 108-128. London: Pluto Press.

James, A. 2007. “Giving Voice to Children's Voices: Practices and Problems, Pitfalls and Potentials." American Anthropologist 109(2):261-272.

Knight, H. 2019. "Centering the Problem Child: Temporality, Colonialism, and Theories of the Child." Global Studies of Childhood 9(1):72-83.

Mahabeer, P. 2018. "Curriculum Decision-makers on Decolonising the Teacher Education Curriculum.” South African Journal of Education 38(4).

Mampane, R.M., Omidire, M.F., Aluko, F.R. 2018. "Decolonising Higher Education in Africa: Arriving at a Glocal Solution.” South African Journal of Education 38(4).

Mbembe, A.J. 2016. "Decolonizing the University: New Directions." Arts \& Humanities in Higher Education 15(1):29-45.

Mignolo, W.A. 2002. "The Geopolitics of Knowledge and the Colonial Difference." South Atlantic Quarterly 101(1):57-96.

Mignolo, W.A. 2011. The Darker Side of Western Modernity. Global Futures, Decolonial Options. Durham: Duke University Press.

Monro, S. 2019. "Non-binary and Genderqueer: An Overview of the Field." International Journal of Transgenderism, doi: $\underline{10.1080 / 15532739.2018 .1538841}$ 
Muller, J., and Young, M. 2019. "Knowledge, Power and Powerful Knowledge Revisited." The Curriculum Journal 30(2):196-214.

Nakata, N.M, Nakata, V., Keech, V., Bolt, R. 2012. "Decolonial Goals and Pedagogies for Indigenous Studies.” Decolonization: Indigeneity, Education \& Society 1(1):120-140.

Neary, M., Newcombe, J., Brown, M.2018. Rightful Lives. http://rightfullives.net/index.html Noxolo, P. 2017. "Decolonial Theory in a Time of the Re-colonisation of UK Research." Transactions 42:342-344.

Prout, A. 2019. “In Defence of Interdisciplinary Childhood Studies.” Children \& Society $33: 309-315$.

Punch, S. 2016. “Cross-world and Cross-disciplinary Dialogue: A More Integrated, Global Approach to Childhood Studies." Global Studies of Childhood 6(3):352-364.

Pursglove, J., and Simpson, M. 2007 "Benchmarking the Performance of English Universities.” Benchmarking: An International Journal 14(1):102-122.

Rudolph, S., Sriprakash, A., Gerrard, J. 2018. "Knowledge and racial violence: the shine and shadow of "powerful knowledge'." Ethics and Education 13(1):22-38.

Sathorar, H., and Geduld, D. 2018. “Towards Decolonising Teacher Education: Reimagining the Relationship between Theory and Praxis." South African Journal of Education 38:4.

Spyrou, S. 2019. “An Ontological Turn for Childhood Studies?” Children \& Society 33:316323.

Spyrou, S., Rosen, R., Cook, D.T. 2019. “Introduction: Reimagining Childhood Studies: Connectivities...Relationalities...Linkages...” In Reimagining Childhood Studies, edited by S. Spyrou, R. Rosen, D.T. Cook, 1-20. London: Bloomsbury. 
Tisdall, E. 2012. "The Challenge and Challenging of Childhood Studies? Learning from Disability Studies and Research with Disabled Children." Children \& Society 26(3):181-191. Thomas, C. 2007. Sociologies of Disability and Illness: Contested Ideas in Disability Studies and Medical Sociology. Hampshire: Palgrave Macmillan.

Twum-Danso Imoh, A. 2016. "From the singular to the plural: Exploring diversities in contemporary childhoods in sub-Saharan Africa." Childhood 23(3):455-468.

UN. 1989. The United Nations Convention on the Rights of the Child. London: UNICEF.

Vilane, V. 2018. "Experiences of Transgender People in Swaziland.” In Queer in Africa: LGBTQI Identities, Citizenship and Activism, edited by Z. Matebeni, S. Monro, V. Reddy. Abingdon: Routledge

Wall, J. 2019. “Theorizing Children's Global Citizenship: Reconstructionism and the Politics of Deep Interdependence. Global Studies of Childhood 9(1):5-17.

Wells, K. 2015. Childhood in a Global Perspective. $2^{\text {nd }} e d$. Cambridge: Polity Press. Wells, K. 2018. Childhood Studies. Making Young Subjects. Cambridge: Polity Press. Wyness, M. 2018. Childhood, Culture and Society in a Global Context. London: Sage. 